\title{
PROFESSORES DE EDUCAÇÃO FÍSICA DAS ESCOLAS PÚBLICAS DA CIDADE DE JATAÍ-GO: VIDA E TRABALHO
}

\author{
Ms. Renata Machado de Assis Gori - Docente do curso de Educação Física/CAJ/UFG \\ Sílvia Helais de Azevedo - Docente de Educação Física da Rede de Educação do Estado \\ de Goiás
}

\section{RESUMO}

A intenção em desenvolver esta pesquisa foi no sentido de verificar as condições de trabalho e de vida social e familiar dos professores de Educação Física que atuam na rede pública de ensino de Jataí-GO. Três categorias de análise se destacaram: a (des)valorização profissional dos professores- extensa jornada de trabalho e professores trabalhando em mais de uma escola; a precariedade das condições físicas e materiais das escolas- inibindo a criatividade $\mathrm{e}$ a possibilidade de fazer um bom trabalho; e as implicações da falta de tempo dos professoresque sofre influência dos baixos salários e dificulta a qualificação continuada, interferindo na vida familiar e social dos docentes.

Palavras- Chave: professores de Educação Física - vida familiar, social e trabalho.

\begin{abstract}
The aim of this research was to verify the working conditions as well as the social and family life of Physical Education teachers that teach in the state schools of Jataí-GO. Three analysis categories were highlighted: the teachers' professional (de)valorization - long day's work and teachers working in more than one school; the precariousness of the schools physical and material conditions - inhibiting creativity and the possibility of doing a good work; and the implications of the teachers' lack of time - which is influenced by the low salaries and complicates the continuity of teachers' qualification, interfering in their family and social life.
\end{abstract} key words: Physical Education teachers, family and social life, work. 


\section{Introdução}

A inquietação por conhecer um pouco mais sobre o cotidiano e a vida profissional e social dos professores de Educação Física do município de Jataí deu origem a este tema de pesquisa, que foi desenvolvida no ano de 2005.

Vários autores que são abordados neste trabalho confirmaram algumas de nossas hipóteses, pois afirmam que a carga de trabalho cansativa impossibilita o professor de se aperfeiçoar continuamente e, em conseqüência disso, surge a desvalorização profíssional, a imagem social ambígua dos professores e a baixa auto-estima, o que por sua vez ocasiona fatores de perturbação e desarticulação nos sistemas de ensino.

A remuneração salarial traz à tona, segundo Cunha (1996), certa mágoa aos professores, por reconhecerem sua desvalorização profissional, afirmando que não existem condições para um exercício absoluto da docência se é necessário sobrecarregar-se de serviço para que se possa sobreviver.

Gatti (1997) indica que para acontecer uma melhoria na qualidade de ensino é necessário que os professores tenham melhora em sua qualidade de vida. Ser professor atualmente é ser cobrado no que se refere a uma formação qualificada e às várias obrigações que a profissão impõe, jogando sobre estes profissionais a responsabilidade das diversas deficiências do sistema de ensino.

Com estes apontamentos, surgem algumas indagações: sobra tempo para o professor participar de momentos familiares, de lazer, religiosos, ingressar em movimentos sociais, etc.? Quais são os seus problemas mais freqüentes? Na opinião dos próprios docentes, o que pode ser mudado para melhorar sua situação profissional e social?

Este estudo tem a relevância de poder investigar os problemas decorrentes da profissão (professor de Educação Física) e verificar se, apesar de tantas dificuldades, o profissional tem a oportunidade de participar de momentos de lazer e convivência social, separando vida profissional e vida particular, de forma a não acarretar prejuízos à sua atuação no processo de ensino.

Inicialmente, foi feita uma explanação sobre a formação de professores, começando pela sua história de vida e pelos motivos que levam a escolha do curso superior e, posteriormente, enfocamos a formação inicial e continuada no curso de Educação Física. 
A formação inicial é importante, pois viabiliza o acesso a novos conhecimentos, contribuindo na formação da personalidade docente. Mas é de suma importância que haja a atualização e a continuidade da qualificação dos profissionais, visto ser, a formação continuada, um dos fatores que influenciam na constituição do "ser professor" e em sua prática docente.

As condições de realização do curso de formação inicial e as possibilidades de qualificação continuada não são as mais favoráveis, na maioria das vezes, ao exercício da profissão docente. Também suas condições de trabalho, seu cotidiano na escola e na vida familiar e social, apresentam, em muitas das vezes, dificuldades e problemas que precisam ser enfrentados.

Após uma incursão teórica abordando todos estes assuntos mencionados (formação inicial, formação continuada e condições do trabalho docente), respaldando-nos em autores como Nóvoa (1995), Perrenoud (1997), Lüdke (1996), Loureiro (1999; 2001), Alves (2005), Gori (2000), Daólio (1995), Betti (1993), Pinheiro (2002), Gatti (2003), Ghedin (2002), Arroyo (1999), Marcellino (2001), Trovão (2001) e Freire (2001), dentre outros, procedemos à exposição e análise dos dados obtidos na pesquisa que buscou verificar, na prática, as condições de vida e trabalho dos professores de Educação Física. São muitas as mazelas, mas a realidade investigada apresenta informações interessantes sobre o que os professores de Educação Física pensam de sua profissão.

\section{A realidade dos professores de Educação Física das escolas públicas}

Este estudo, do tipo qualitativo-descritivo, buscou conhecer a realidade em que vivem os professores de Educação Física das escolas públicas de Jataí, seus problemas e as oportunidades de convívio com a sociedade no seu cotidiano.

Inicialmente foi realizada uma pesquisa exploratória, para obtermos um conhecimento prévio das escolas públicas (estaduais e municipais) que oferecem aulas de Educação Física, bem como o número exato de professores desta disciplina, seus nomes, respectivos endereços e telefones, e ainda a escola onde são lotados. A escolha das escolas públicas se deu a partir da hipótese de que os salários geralmente são inferiores aos das escolas particulares e os problemas/dificuldades com recursos didáticos, as cargas horárias exaustivas e a baixa remuneração salarial são mais freqüentes. ${ }^{1}$

\footnotetext{
${ }^{1}$ A preocupação com estas condições de trabalho (que parecem ser precárias, mas que precisam ser investigadas) deu origem a outra pesquisa sobre a opção dos professores de Educação Física pela área escolar como campo de atuação escolar, que está em andamento e será apresentada no V Simpósio de Educação do Sudoeste Goiano, no
} 
Portanto, os sujeitos deste trabalho foram todos os professores de Educação Física das escolas públicas de ensino da cidade de Jataí - GO, quatorze que atuam na rede municipal e de igual número na rede estadual. Um professor da rede municipal não foi encontrado para responder às perguntas e uma professora da rede estadual não respondeu o formulário, por opção, totalizando, portanto, 26 sujeitos. Não participaram deste grupo de sujeitos os professores que estavam em licença durante o período em que se realizou a pesquisa de campo.

A pesquisa de campo se desenvolveu através da aplicação de formulário, como instrumento de coleta de dados, utilizando questões abertas e de múltipla escolha, que enfocaram: suas características tais como: sexo, idade, estado civil, instituição na qual se formaram, ano de conclusão do curso e tempo de trabalho na escola e na rede pública; se os professores trabalham apenas em uma escola ou também em outro local (escola ou não); se existem dificuldades em dar aulas na rede pública de ensino e quais são elas; se estas dificuldades (caso existam) interferem na prática pedagógica cotidiana; aspectos considerados por eles como "frustrantes" e como "gratificantes" em sua atuação profissional; se as expectativas docentes foram atendidas de alguma forma ou se existe a vontade de mudar de profissão; se os professores consideram seu salário suficiente para sobreviver e suas justificativas para a resposta dada; se o salário que recebem é a única fonte de renda da família ou se existem outras; se já participaram de cursos de qualificação que contribuíram com sua prática pedagógica e qual foi a data do último cursado; se houve apoio da escola para a realização deste tipo de curso ou se enfrentaram dificuldades e buscaram alternativas para fazê-lo; se participam de algum grupo político, religioso, filantrópico, etc.; se participam, quais são os motivos que os levam a freqüentar este tipo de grupo; de que forma eles conseguem conciliar sua prática docente com momentos de lazer e de convivência social no dia-a-dia; qual é a freqüência de momentos de descontração e lazer com a família e amigos, se existir esta oportunidade em suas vidas; quais são os locais freqüentados pelos professores em suas horas vagas (de lazer); se eles praticam atividades físicas regularmente, por que motivo, com que freqüência, e quais são as preferidas por eles. Finalmente, perguntamos o que poderia ser mudado para que os problemas referentes à sua profissão fossem sanados ou minimizados, na opinião de cada um dos sujeitos.

A análise dos dados se deu através da classificação e tabulação das respostas objetivas, e da seleção de pontos em comum ou divergentes nas respostas subjetivas. 
Utilizamos as informações concedidas pelos sujeitos e as apresentamos, respaldando-nos em autores da área para discutir os dados. Durante este processo, foi possível perceber três categorias de análise que emergiram do discurso dos sujeitos: a (des)valorização profíssional dos professores; a falta de estrutura física e material para as aulas de Educação Física; e as conseqüências da falta de tempo na vida dos professores.

\section{A (des)valorização profissional dos professores}

Atualmente a valorização dos professores é muito discutida, e a extensa jornada de trabalho e os baixos salários são fatores de grande influência no prestígio da profissão docente. A partir das informações obtidas, pudemos conhecer a realidade vivida por eles em sua profissão.

A valorização profissional pelo aumento salarial foi questionada por onze professores que responderam que seus salários não são suficientes para atender a todas as suas necessidades, e a diminuição da carga horária pelo conseqüente aumento salarial é a solução, na opinião de um dos sujeitos, o que permitiria a cada docente ministrar aulas em uma única escola.

Um dos professores acredita que, para que isto mude, é necessário o reconhecimento do trabalho realizado pelos docentes, o que requer uma mudança também na forma de pensar dos governantes.

Para nove professores, seu salário é suficiente para suas despesas. Uma justificativa plausível para estas respostas pode ser o fato de serem, em sua maioria, solteiros, ou seja, não têm muitos gastos. No caso dos professores casados, eles têm o salário do(a) companheiro(a), que auxilia nas despesas. Os professores que não têm o curso superior de Educação Física (denominados nesta pesquisa de "leigos") também não questionam seus baixos salários, mostrando-se satisfeitos com o que ganham.

Um sujeito justifica sua opinião, sobre seu salário ser suficiente, dizendo que há pessoas que sobrevivem ganhando menos do que o salário do professor público, o que denota certo conformismo com sua situação trabalhista.

No entanto, um dos sujeitos se posiciona de forma contrária aos anteriores. Diz que não ganha bem, embora pareça um bom salário porque a maioria da população brasileira ganha até menos do que isto. Explica que para as necessidades básicas o valor ganho é suficiente, mas não são permitidos imprevistos ou gastos não planejados. Este docente ainda se queixa de que tem que trabalhar em três escolas para conseguir ganhar o que está recebendo atualmente. 
Darido e Silva (2002) colocam que no Brasil os professores, em sua maioria, estão estruturados de modo que são contratados por hora-aula e trabalham em várias instituições. Esteve (1995) afirma que a desvalorização salarial produziu-se por uma desvalorização social da profissão, e Souza (1996) complementa que o aumento salarial seria a única forma de favorecer a redução da carga de trabalho do professor. No entender de Costa (1995), para ser professor é exigido um alto nível de especialização constantemente, e por exigir tanto do professor ele não deve receber como trabalhadores assalariados que não necessitam estar periodicamente se especializando e lidando com o conhecimento que é atualizado constantemente.

Para que o professor realize um trabalho de qualidade, receber um salário digno que atenda às suas necessidades é de fundamental importância, visto que ele determina em quantos lugares deve-se trabalhar para se conseguir o suficiente para sua subsistência. A sobrecarga de trabalho pode comprometer o tempo disponível para planejar e atualizar seus conhecimentos, bem como seus momentos de descanso.

No entanto, apesar das dificuldades oriundas desta profissão, os professores apontaram os pontos positivos de "ser professor". Alguns deles mencionaram o prazer de contribuir para a formação moral do aluno, o reconhecimento, a convivência e o aprendizado que é compartilhado com o aluno, os resultados das aulas no aprimoramento de suas habilidades e, por fim, citaram a eterna busca do professor pelo conhecimento.

Um sujeito demonstra o prazer em contribuir para a formação moral do aluno, propiciando a educação de cidadãos críticos. Ele diz se satisfazer ao perceber a construção de valores, opiniões e críticas por parte dos alunos. Outro professor cita, como ponto positivo desta profissão e como grande responsabilidade, a oportunidade de participar ativamente na formação cultural e comportamental do educando.

Foi possível perceber nas respostas de três professores que a gratificação da docência vem pelo reconhecimento do aluno, através do prazer e da satisfação que eles apresentam nas aulas e do convívio cotidiano. A amizade e o afeto são citados como sentimentos presentes no exercício da profissão, em contato com os discentes. Um sujeito menciona o convívio direto com os alunos, o que propicia novas aprendizagens através da troca de experiências e conhecimentos.

Segundo Dayrell (2005), para alguns a docência é um sacerdócio, uma missão, e para outras uma "cachaça", outros se sentem com alegria e prazer e há alguns que a consideram como extensão da maternidade. Daólio (1995) coloca que muitos professores de 
Educação Física a escolhem por ideal de vida, o que fica explícito também na fala de um dos sujeitos.

Bueno e Lapo (2005) citam Bohoslavsky, e dizem que se o indivíduo pensa em uma profissão, ele pensa em algo que se relaciona com a realização pessoal, a felicidade, a alegria de viver, etc., como quer que isto seja entendido (p.12), e quando o envolvimento, com esse "algo", deixa de resultar em sua realização pessoal, a tendência certamente é diminuir o envolvimento e os esforços para com a profissão. Não há dúvida que o trabalho docente oferece importantes motivos de satisfação intrínseca. (IBARROLA, 1998, p. 73)

Por mais que se tenha dito, a docência, do modo que está, mal remunerada e pouco vista pelos governantes, ainda conta com seus pontos positivos e com pessoas que pensam no futuro, ao participar da formação moral do seu aluno, construindo relações. Apesar de se pagar mal, ainda há uma forma de "prender" seus professores na escola.

Ao falarmos em dificuldades, algumas foram pontuadas nas falas dos professores, principalmente nas dos leigos, que relatam apresentar maiores dificuldades em dar aulas, e gostariam que o órgão empregador fizesse um maior acompanhamento. Sugeriram maiores possibilidades de participação em cursos e palestras, atendimento pedagógico (com os coordenadores de área), e um dos sujeitos disse que gostaria de ganhar "receitas de bolo" para serem aplicadas em suas aulas, pois encontra dificuldades na prática diária, referentes à falta de recursos pedagógicos e à falta de orientação de uma pessoa qualificada.

Darido e Silva (2002) dizem que a reflexão tem primordial importância na formação inicial, o que proporciona uma atuação profissional de qualidade, e tem papel de destaque no curso de Educação Física, possibilitando que o professor possa ter constante reflexão-anterior, durante e após a ação (p. 160) no ensino-aprendizagem das modalidades esportivas. Os professores leigos, em sua maioria, logo pensam em objetivar práticas concretas, não se perguntando sobre a subjetividade implicada em cada exercício proposto, constituindo-se em uma grande dificuldade, para eles, não terem uma participação do órgão empregador na elaboração das aulas, ao dizer a eles o que oferecer em cada aula.

2 A precariedade das condições físicas e materiais das escolas

Nesta segunda categoria de análise, os professores relataram as dificuldades em dar aulas na rede pública. A maioria deles, quinze sujeitos, respondeu que é precária a infraestrutura da escola; outros seis acreditam que a maior dificuldade é a pouca quantidade de recursos materiais; e em complemento, outros cinco professores se queixaram de que com estas dificuldades fica difícil dar aulas de melhor qualidade. 
Um sujeito menciona que uma das maiores dificuldades e que interfere na participação dos alunos nas aulas é a precária condição física da escola. A quadra apresenta buracos no piso e não tem cobertura, impossibilitando as aulas neste local em dias de chuva ou de sol muito forte. Isto inibe a criatividade, tanto dos professores quanto dos alunos, e restringe, também, a possibilidade de fazer um bom trabalho. Um sujeito que ministra aulas na escola rural comenta que as aulas são realizadas em um campo de terra, o que prejudica ainda mais as atividades, devido à poeira, e não há como diversificar o esporte a ser trabalhado, que acaba sendo sempre o futebol por exigir menos estrutura.

Outro problema referente à infra-estrutura, mencionado por dois outros professores, é de que logo após as aulas de Educação Física, que são realizadas no turno regular, os alunos não têm como utilizar vestiários para que seja feita uma higienização adequada antes de retornem para a sala de aula. A falta de estrutura física para manter esta disciplina no mesmo período das aulas é questionada pelos professores da rede estadual.

É comum a resistência dos alunos em participar da aula de Educação Física, pelo vestuário inadequado e por terem aula depois. E a falta de recursos materiais é mais complexa ainda pelo fato de as turmas serem superlotadas, como dizem dois dos professores.

Oliveira (2005) comenta que as péssimas condições de trabalho dos docentes são aspectos claramente decorrentes do modo como o estado administra a educação e o ensino público. A LDB deixa livre para a escola escolher o melhor horário para que sejam realizadas as aulas, bem como a separação por sexo, ou juntar turmas diferentes e até mesmo reduzir ou aumentar o número de aulas de Educação Física (SOUZA e VAGO, 1997).

É muito difícil pensar que as escolas sejam bem estruturadas para que as aulas de Educação Física sejam realizadas no turno regular, por ser notório que a cada ano é investido menos em Educação, e construir vestiários ou quadras cobertas para as aulas de Educação Física apresenta-se como uma realidade muito distante.

3 As implicações da falta de tempo dos professores

Nesta categoria abordaremos as conseqüências que a falta de tempo, que aqui se encontra em estreita relação com os salários dos professores, pode trazer à vida dos professores, ocasionando a não atualização, e a pouca disposição para fazer um bom trabalho. Mas falta de tempo não é desculpa para a não prática de atividade física e lazer, para a maioria dos professores.

A escassez de tempo e os baixos salários são justificativas para a não atualização dos professores. Onze deles mencionaram que quando realizaram os cursos de especialização 
os fizeram aos finais de semana e somente seis deles foram dispensados de dar aulas na escola durante seu período de duração.

Nos dizeres de Libâneo (1997), para que se tenha maior qualidade nas aulas, é necessário investimento na formação continuada dos professores, ao mesmo tempo em que deve ser feita a revisão dos salários. Souza (1996) nos diz que a qualificação docente é importante, pois de um lado se mantém atualizado sobre as produções científicas da sua área, e por outro, é capaz de responder com criatividade às diversas situações colocadas pelo coletivo de alunos, construindo no cotidiano uma fonte de aprendizado.

Nacarato, Varani e Carvalho (1998) completam que a impossibilidade de se aperfeiçoar constantemente é remetida à falta de tempo, impedindo o professor, de preparar e refletir criticamente sobre sua prática pedagógica. Marchesi (2002) comenta que a escassa formação e a falta de tempo dedicado à reflexão podem vir a manter na prática do professor modelos de ensino que sejam, ao mesmo tempo, tradicionais e repetitivos.

Os professores, em sua maioria, trabalham pelo menos em dois períodos do dia, toda semana, e há professores que trabalham durante os três períodos. Participar de cursos de qualificação aos finais de semana, que é o que foi descrito pela maioria dos professores, tornase muito cansativo e desestimulante, por ocupar o seu tempo de descanso, convivência familiar e participação social, sem falar nos momentos em que estão planejando suas aulas.

Segundo Santos (1999), o computador é um instrumento imprescindível para a distribuição e a difusão do conhecimento, sendo inegável que pela internet é acelerada a circulação de um grande número de jornais, revistas e também são realizados diferentes encontros e discussões científicas.

O desenvolvimento de novas tecnologias, segundo Stahl (1997) assume um ritmo crescente e imprime na sociedade novos rumos sócio-econômicos e culturais. E sua apropriação permite ao professor selecionar e explorar as tecnologias adequadas ao seu contexto específico, que será usado na educação, ampliando o conhecimento dos alunos. Este conhecimento adquirido, segundo o autor, não é apenas transmitido em aulas ou armazenado em livros, e sim se constrói nas experiências do dia-a-dia, através de uma multiplicidade de meios. O professor participando destas novas tecnologias terá a noção clara de seu potencial educativo para si e seus alunos.

Visto que a sociedade está cada vez mais informatizada, os professores deveriam acompanhar este avanço, mas isso não é possível. Por mais que algumas escolas tenham um laboratório de informática, o professor não consegue ter acesso a ele pela falta de tempo, sendo de muita importância que ele tenha este recurso disponível em sua casa, para ser usado 
quando tiver disponibilidade. Mas esta não é a realidade da grande maioria dos professores que participou desta pesquisa. A justificativa desta situação é, mais uma vez, a falta de condições financeiras para investir em um computador.

Quanto ao tempo para a participação em atividades físicas, encontramos dezenove professores que praticam atividades físicas regulamente, pelo menos três vezes na semana, e apenas seis professores não praticam nenhum tipo de atividade. Um sujeito justificou que não tem tempo, pelo fato de trabalhar nos três períodos. Outro, além da sobrecarga de trabalho também, mencionou a falta de condições financeiras para freqüentar uma academia. Os outros quatro professores disseram que simplesmente não praticam por acomodação.

Dentre os professores que praticam atividades físicas regularmente, há a preferência em primeiro lugar por esportes coletivos, em segundo por atividades ao ar livre, e em terceiro por atividades aquáticas. Um sujeito explica que participa deste tipo de atividades porque acha importante para o corpo e porque treina atletismo. Mas a maioria dos sujeitos justificou a prática para a manutenção da saúde, do bem-estar físico e emocional.

Trovão (2002, p. 183) comenta que: a prática desportiva poderá (deverá, julgamos nós) contribuir decisivamente, em muitos casos, para que seja melhorada a qualidade de vida. Segundo o autor, a qualidade de vida com a prática de atividade física pode variar de indivíduo para indivíduo e o desporto só tem razão de existir se valorizar e melhorar a sua qualidade de vida.

A prática da atividade física, no entender de Weineck (2002), além de trazer influência positiva sobre fatores de risco a doenças cardiopulmonares, ativa a produção de hormônios que afetam o bem-estar psíquico, diminuindo sentimentos de depressão e ansiedade. Os benefícios das atividades físicas são enormes, e o professor pode ter a acesso a esta prática na intenção de diminuir o cansaço adquirido na sua extensa jornada de trabalho, reapresentando uma forma para que seus problemas cotidianos não interfiram em sua prática pedagógica, e seus alunos possam ter menos prejuízos nas aulas de Educação Física.

Quando os professores foram questionados sobre a participação em grupos políticos, religiosos e associações como meio de convivência social, doze responderam que têm participação regular e quatorze não participam. Um sujeito diz que participa pelo contato que pode manter com as outras pessoas. Outros dizem que freqüentam grupos religiosos para cuidarem de sua espiritualidade. Um dos professores participa de um grupo esportivo por ser uma atividade prazerosa e porque faz parte de um grupo de amigos que fundou uma agremiação esportiva. Outro participa de organização sindical porque diz se importar com o coletivo e com as condições de trabalho de sua classe docente. Há ainda um sujeito que 
participa de um grupo de auto-ajuda, e sua intenção é ajudar as pessoas. Ele foi alcoólatra e espera, através deste grupo, auxiliar outros indivíduos a deixarem este vício, a exemplo dele.

Uma professora comenta que a burocracia exigida pelas escolas e o excesso de atividades levadas para casa são coisas que atrapalham seus momentos de convivência social, que quando existem são apenas aos finais de semana, mesmo assim se tiver dinheiro, fato que geralmente não ocorre.

Nacarato, Varani e Carvalho (1998) colocam que o sistema burocrático contribui para a desqualificação do professor na medida em que é necessário que ele faça a chamada, lance a matéria dada etc., mas reconhece que é a única forma de se ter controle do trabalho do professor. Isso gera o aumento de uma desqualificação intelectual do docente, pois, ao ter que cumprir mais essas tarefas, reduz o seu tempo disponivel para estudos individuais ou em grupos. (p.87).

Os professores de Educação Física, quando questionados sobre os locais freqüentados em seus momentos de horas vagas, citaram com maior freqüência: clubes, lagos, fazendas, outras cidades vizinhas, barzinhos e praças. Quatorze professores responderam que freqüentam estes lugares pelo menos todos finais de semana, dez responderam que freqüentam nos períodos de férias e seis deles freqüentam pelo menos duas vezes por semana.

Para os professores conseguirem conciliar sua profissão com momentos de lazer, ainda não é uma tarefa muito fácil, principalmente para aqueles que trabalham em mais de uma escola e nos três períodos do dia. Para muitos professores, a melhor opção é estabelecer metas e prioridades, tentando separar o tempo para cada atividade. Alguns deles afirmam que, para conseguirem ter momentos de lazer e convivência social, têm que reservar com antecedência o tempo destinado a eles e cumpri-lo rigorosamente, caso contrário não sobra tempo.

Alguns professores têm a aula de Educação Física como momentos de muito prazer, conciliando a prática pedagógica com momentos que consideram como sendo de lazer. Outros dão prioridade às atividades docentes, em detrimento dos seus momentos de lazer.

Camargo (1999) diz que lazer e trabalho podem ser confundidos por uma minoria da população, e se para todos fosse assim, as pessoas poderiam desenvolver sua profissão com muito mais dedicação. Complementa que isto é difícil de ocorrer, visto que a própria organização do espaço de trabalho inibe qualquer tentativa de diversão e entretenimento. (p.36) 
As atividades pedagógicas dos professores, segundo Libâneo (1997), podem compartilhar de um mundo cultural e científico, mas por condições salariais é impossibilitado de participar do mundo da produção cultural e artística, das teorias e dos discursos.

Percebemos que o excesso de trabalho dos professores os atrapalha quando querem se qualificar, descansar e até conviver socialmente e em seus momentos de lazer. Uma minoria tem a oportunidade de freqüentar museus e poderia ser possível que eles pudessem viajar para outros países, para participar de congressos, em busca de aperfeiçoar seus conhecimentos, mas dentre os pesquisados ninguém manifestou ter condições para tal possibilidade. O lazer representa um momento importante na vida do professor que, além de relaxar, pode adquirir conhecimentos específicos.

\section{Algumas considerações}

Esta pesquisa, em um primeiro momento, comentou sobre a formação inicial, quando falamos da formação da identidade do indivíduo e suas manifestações. Conseqüentemente discorremos sobre a escolha do curso superior, que depende da identificação do sujeito com a profissão a ser seguida, mas que também sofre outras influências no momento da opção. Mencionamos também a formação continuada e sua importância na profissão docente, qualificando os professores para as diferentes situações encontradas na sua prática.

Em um segundo momento, abordamos a interferência do cotidiano na vida dos professores e a relevância da qualidade de vida que assegura às pessoas o bem-estar físico e emocional, favorecendo o trato com o conhecimento. Comentamos também as dificuldades que os professores das escolas públicas normalmente enfrentam, como a extensa jornada de trabalho e a questão da desvalorização profissional e que tem o salário baixo como um dos seus responsáveis.

Constatamos, através de nossa pesquisa, segundo o relato dos professores, que a precária infra-estrutura das escolas e a falta de recursos didáticos influenciam na qualidade das aulas. A prática das aulas de Educação Física, no mesmo turno que os alunos estudam, fica prejudicada pela falta de infra-estrutura, pois a maioria dos alunos não vai com vestimenta adequada, recusa-se a participar das aulas e mesmo que eles participem, não tem condições de realizar sua higiene pessoal após a aula de modo satisfatório.

A questão financeira foi citada com muita ênfase pelos sujeitos e interfere na maioria das dificuldades enumeradas por eles. Os baixos salários exigem que os professores 
se sobrecarreguem com mais de um emprego, com extensas horas de trabalho, e limitem suas possibilidades de lazer, de qualidade de vida e de qualificação (educação continuada), planejamento e descanso. Contraditoriamente, alguns se sentem satisfeitos com os valores recebidos, ressaltando que é suficiente para atender suas necessidades básicas (moradia, alimentação e vestuário).

Esta pesquisa não teve a intenção de responder às inúmeras questões provenientes da vida cotidiana dos professores de Educação Física, mas de levantar informações referentes a esta profissão, enumerando as dificuldades e facilidades encontradas por estes profissionais, tanto junto à sua família quanto na vida em comunidade. Mas isto é apenas um começo, pois a discussão ainda é incipiente e requer prosseguimento.

\section{REFERÊNCIAS BIBLIOGRÁFICAS}

ALVES, Ana Elizabeth Santos. Sonho e realidade do licenciado no mercado de trabalho. Educação on-line, 05/03/2004. In: www.educaçãoonline.pro.br, em 23/06/2005.

ARROYO. Miguel G. As relações sociais na escola e a formação do trabalho. In: FERRETTI, Celso João; SILVA JÚNIOR, João dos Reis; OLIVEIRA, Maria Rita Neto Sales (Orgs.). Trabalho, formação e currículo: para onde vai a escola? São Paulo: Xamã, 1999, p. 13-42.

BETTI, Mauro. Perspectivas na formação profissional. In: MOREIRA, Wagner Wey (Org.). Educação Física e Esportes: perspectivas para o século XXI. Campinas, SP: Papirus, 1993, p. 239-254.

BUENO, Belmira Oliveira; LAPO, Flavinês Rebolo. Professores, desencanto com a profissão e abandono do magistério. Cadernos de pesquisa, 2003. In: www.scielo.br, em 20/08/2005.

CAMARGO, Luiz Octávio Lima. O que é o lazer. São Paulo: Brasiliense, 1999.

COSTA, Marisa Cristina Vorraber. Trabalho docente e profissionalismo. Porto Alegre: Sulinas, 1995.

CUNHA, Maria Isabel da. O bom professor e sua prática. 6 ed. Campinas, SP: Papirus, 1996.

DAÓLIO, Jocimar. Da cultura do corpo. São Paulo: Papirus, 1995.

DARIDO, Suraya Cristina; SILVA, Eduardo Vinicius Mota. O papel das disciplinas esportivas na formação profissional em Educação Física. In: MOREIRA, Wagner Wey; SIMÕES, Regina (Orgs.). Esporte como fator de qualidade de vida. Piracicaba, SP: UNIMEP, 2002, p. 151-162. 
DAYRELL, Juarez Tarcisio. Escola e diversidade cultural: considerações em torno da formação humana, Educação on-line, 23/08/2001. In: www.educacaoonline.pro.br, em 19/09/2005.

DOURADO, Luiz Fernandes. A formação inicial e continuada de professores à distância no Brasil: um caminho para a expansão da educação superior? In: LISITA, Verbena Moreira Soares de Souza; PEIXOTO, Adão José (Org.). Formação de professores: políticas, concepções e perspectivas. Goiânia: Alternativa, 2001, p. 69-80.

ESTEVE, José M. Mudanças sociais e função docente. In: NÓVOA, Antônio (Org.). Profissão-Professor. Portugal: Porto Codex, 1995, p. 93-124.

FREIRE, João Batista. A educação dos sentidos e a qualidade de vida: a escola de dona Clotilde. In: MOREIRA, Wagner Wey (Org.). Qualidade de vida: complexidade e educação. Campinas, SP: Papirus, 2001, p. 107-122.

GATTI, Bernadete Angelina. Formação de professores e carreira: problemas e movimentos de renovação. Campinas, SP: Autores Associados, 1997.

GATTI, Bernadete Angelina. Formar professores: velhos problemas e demandas contemporâneas. Educação e contemporaneidade, Salvador, n.20, p. 469-479, 2003.

GHEDIN, Evandro. Professor reflexivo: da avaliação da técnica à autonomia da crítica. In: PIMENTA, Selma Garrido; GHEDIN, Evandro (Orgs.). Professor reflexivo no Brasil e crítica de um conceito. São Paulo: Cortez, 2002, p. 129-139.

GORI, Renata Machado de Assis. A inserção do profissional iniciante de Educação Física na escola. Belo Horizonte: UFMG/FAE, 2000. Dissertação (Mestrado) -Faculdade de Educação -Universidade Federal de Minas Gerais, 2000.

IBARROLA, Maria de. A recente experiência mexicana de formação básica e contínua de professores. In: SERBINO, Raquel Volpato et al. Formação de professores. São Paulo: UNESP, 1998, p. 69-84.

LIBÂNEO, José Carlos. Pedagogia e modernidade presente e futuro da escola. In: GHIRALDELLI JÚNIOR, Paulo (Org.). Infância, escola e modernidade. São Paulo: Cortez, 1997, p. 127-176.

LOUREIRO, Walderês Nunes (Org.). Formação e profissionalização docente. Goiânia: UFG, 1999. Cap.06: Profissionalização. p. 79-84.

Formação de professores: realidade e perspectivas. In: LISITA, Verbena Moreira Soares de Souza; PEIXOTO, Adão José (Org.). Formação de professores: políticas, concepções e perspectivas. Goiânia: Alternativa, 2001, p. 59-74.

LÜDKE, Menga. Formação inicial e construção da identidade profissional de professores de $1^{\circ}$ grau. In: MIZUKAMI, Maria da Graça Nicoletti; REALI, Aline Maria de Medeiros Rodrigues. Formação de professores: tendências atuais. São Carlos, SP: EDUFSCar, 1996, p. $25-46$. 
MARCELLINO, Nelson Carvalho. Lazer e qualidade de vida. In: MOREIRA, Wagner Wey (Org.). Qualidade de vida: complexidade e educação. Campinas, SP: Papirus, 2001, p. 45-60.

MARCHESI, Álvaro. Educação para a mudança. In: MARFAN, Marilda Almeida (Org.). Congresso brasileiro de qualidade na educação: formação de professores. Brasília: MEC/ SEF, 2002, p. 17-23.

NACARATO, Adair Mendes; VARANI, Adriana; CARVALHO, Valéria de. O cotidiano do trabalho docente: palco, bastidores e trabalho invisível... Abrindo as cortinas. In: FIORRENTINI, Dario; GERALDI, Corinta Grisolia; PEREIRA, Elizabete Monteiro de Aguiar (Org.). Cartografias do trabalho docente: professor(a)-pesquisador(a). Campinas, SP: Mercados de Letras/Associação de Leitura do Brasil-ALB, 1998, p. 173-104.

NÓVOA, António (Org.). Vidas de professores. Portugal: Porto Codex, 1995. Cap.1: Os professores e as histórias da sua vida, p. 11-32.

OLIVEIRA, Dalila Andrade. A reestrutura do trabalho docente: precarização e flexibilidade. Cadernos Cedes. Campinas, SP, n. 89, 2004, In: www.scielo.br, em 20/08/2005.

PERRENOUD, Philippe. Práticas pedagógicas, profissão docente e formação: perspectivas sociológicas. Lisboa-Portugal: Nova Enciclopédia, 1997.

PINHEIRO, Luis Felipe Camargo. O processo reflexivo e a tomada de consciência do professor multiplicador. In: CELANI, Maria Antonela Alba (Org.). Professores formadores em mudanças: relato de um processo de reflexão e transformação da prática docente. Campinas, SP: Mercado de Letras, 2002, p. 175-190.

SANTOS, Lucíola Licínio. Saberes escolares e o mundo do trabalho. In: FERRETTI, Celso João; SILVA JÚNIOR, João dos Reis; OLIVEIRA, Maria Rita Neto Sales (Orgs.) Trabalho, formação e currículo: para onde vai a escola? São Paulo: Xamã, 1999, p. 63-74.

.Pesquisa e ensino In: LISITA, Verbena Moreira Soares de Souza; PEIXOTO, Adão José (Org.). Formação de professores: políticas, concepções e perspectivas. Goiânia: Alternativa, 2001, p. 19-83.

SOUZA, Aparecida Néri de. Sou professor, sim senhor! : representações do trabalho docente. Campinas, SP: Papirus, 1996.

SOUZA, Eustáquia Salvadora de; VAGO, Tarcísio Mauro. O ensino da Educação Física em face da nova LDB. In: CBCE, Colégio Brasileiro de Ciências do Esporte (Org.). Educação Física escolar frente à LDB e aos PCNs: profissionais analisam renovações modismo e interesses. Ijuí, RS: Sedigraf, 1997, p. 121-141.

STAHL. Marimar M. Formação de professores para uso das novas tecnologias de comunicação e informação. In: CANDAU, Vera Maria (Org.). Magistério: construção cotidiana. 2 ed. Petrópolis, RJ: Vozes, 1997, p. 292-317.

TROVÃO, Rosário do. Qualidade de vida: juventude, idade adulta e educação. In: MOREIRA, Wagner Wey (Org.). Qualidade de vida: complexidade e educação. Campinas, SP: Papirus, 2001, p. 157-168. 
Cuidemos do nosso jardim. In: MOREIRA, Wagner Wey; SIMÕES, Regina (Orgs.). Esporte como fator de qualidade de vida. Piracicaba, SP: UNIMEP, 2002, p. 181-190.

WEINECK, Jurgen. $A$ influência do treinamento sobre os hormônios: sua importância para o bem-estar psicofísico. In: MOREIRA, Wagner Wey; SIMÕES, Regina (Orgs.). Esporte como fator de qualidade de vida. Piracicaba, SP: UNIMEP, 2002, p. 63-84. 